\title{
African Americans and Cancer: A Minority Health Advocacy
}

\section{Anita Mandal, Noor K Islam, Judy Scott, Benjamin Okafor and Prabir K Mandal ${ }^{*}$}

Edward Waters College, 1658 Kings Road, Jacksonville, FL 32209, USA

African American suffers significantly more cancer morbidity and mortality than the white population. In order to decrease this differential, it is critical to understand the particular barriers to health and health care that underserved African Americans face. The barriers have been identified as: inadequate access to and availability of health care services, lack of knowledge of cancer prevention and screening recommendations, low literacy, mistrust of the health care system, fear and fatalism regarding cancer cure. The National Cancer Institute (NCI) defines "Cancer Health Disparities" as adverse differences in cancer incidence (new cases), cancer prevalence (all existing cases), cancer death (mortality), cancer survivorship, and burden of cancer or related health conditions that exist among specific population groups in the United States. The United States Census Bureau estimates that in 2013 there are nearly 42 million African Americans living in the United States, comprising 13 percent of the total population[1]. In 2010, nearly one out of every four African Americans resided in New York, Florida, or Texas [2]. Of the more than 3 million foreign-born African Americans, the majority were born in the Caribbean (53\%) or Africa (35\%)[3].

Cancer ranks second only to cardiovascular disease as the leading cause of death in the United States. Cancer is a group of diseases characterized by uncontrolled growth and spread of abnormal cells. Cancer is caused by both external factors (tobacco, infectious organisms, poor nutrition, chemicals, and radiation) and internal factors (inherited genetic mutations, hormones, immune conditions, and mutations that occur from metabolism). These causal factors may act together or in sequence to initiate or promote the development of cancer. African Americans have the highest death rate and shortest survival of any racial and ethnic group in the United States for most cancers. The causes of these inequalities are complex and are thought to reflect social and economic disparities more than biological differences associated with race. Socioeconomic disparities include inequalities in work, wealth, income, education, housing and overall standard of living, as well as barriers to high-quality cancer prevention, early detection, and treatment services. Overall, about 1 in 2 African American men and 1 in 3 African American women will be diagnosed with cancer in their lifetime and the lifetime probability of dying from cancer is about 1 in 4 for African American men and 1 in 5 for African American women. The National Cancer Institute estimates that approximately 1,045,935 African American with a history of cancer were alive on January 1, 2009 [4].

A substantial proportion of cancer cases and deaths could be prevented with the adoption of healthier lifestyles, such as avoiding tobacco products, maintaining a healthy body weight, and being physically active. For example, a large proportion of colorectal cancers could be prevented by avoiding risk factors such as obesity, physical inactivity, and high consumption of red and processed meat. Cervical cancers, which are caused by persistent infection with Human Papillomavirus (HPV), could be prevented by vaccination against cancer-causing types of HPV. Among males, incidence and death rates are higher among African Americans than whites for all cancers combined and for the most common cancers (including prostate, lung, colorectal, kidney, and pancreas). In contrast, African American women have a lower risk of cancer overall than white women, largely due to lower incidence rates for the two most common cancers, breast and lung. Incidence rates for Kaposi Sarcoma (KS), stomach cancer, and multiple myeloma are about twice as high in African Americans compared to whites. The incidence rates of KS are 2.7 times higher in African American men compared to white men and 3.6 times higher in African American women compared to white women. In the US, KS primarily occurs among people infected with Human Immunodeficiency Virus (HIV). Higher rates of stomach cancer in African Americans are limited to non-cardia gastric cancers which may reflect higher rates of Helicobacter pylori infection. High consumption of salt and grilled meat also increases risk [5].

African Americans have lower 5-year survival than whites overall and for each stage of diagnosis for most cancers sites. Much of the difference in survival is believed to be due to barriers that limit access to timely, high-quality medical care [6-11]. Furthermore, African Americans are more likely to be diagnosed at a later stage of disease, when treatment choices are more limited and less effective. These issues are recognized to largely reflect socioeconomic disparities associated with race.

Breast cancer is the most commonly diagnosed cancer among African American women. Breast cancers diagnosed in African American women are more likely to have factors associated with poor prognosis, such as higher grade, advanced stage, and negative hormone (estrogen [ER] and progesterone [PR]) receptor status [12-14]. Studies have shown that certain reproductive patterns that are more common among African American women (including giving birth to more than one child, younger age at menarche, early age at first pregnancy), may be associated with increased risk for aggressive subtypes of breast cancer [15]. The most common gene mutations of BRCA1 and BRCA2 are associated with the breast cancer.

Cervical cancer is almost always caused by persistent genital Human Papillomavirus (HPV) infection. The incidence rate of cervical cancer is 34\% higher in African American than white women. Cervical cancer is one of only two cancers (colorectal is the other) that can actually be prevented through screening with routine Pap tests or through the HPV vaccine.

Colorectal cancer (CRC), often referred to as colon cancer, develops in the colon or the rectum. Colon cancer is the third most common cancer in both African American men and women. Major modifiable factors that increase risk for colorectal cancer include obesity, diabetes,

${ }^{*}$ Corresponding author: Prabir K Mandal, Professor, Department of Biology, Edward Waters College, USA, Tel: 904-619-4721; E-mail: prabir.mandal0807@ewc.edu

Received November 26, 2014; Accepted November 27, 2014; Published December 01,2014

Citation: Mandal A, Islam NK, Scott J, Okafor B, Mandal PK (2014) African Americans and Cancer: A Minority Health Advocacy. J Bioprocess Biotech 4:e117 doi: $10.4172 / 2155-9821.1000 \mathrm{e} 117$

Copyright: $\odot 2014$ Mandal A, et al. This is an open-access article distributed under the terms of the Creative Commons Attribution License, which permits unrestricted use, distribution, and reproduction in any medium, provided the original author and source are credited. 
high consumption of red or processed meats, alcohol consumption, and smoking. Studies consistently report that regular physical activity is associated with a lower risk of colon cancer [16]. The majority of CRC can be prevented with proper screening, early detection and removal of adenomatous polyps.

Lung cancer is the second most common cancer in both African American men and women. Lung cancer is the top cancer killer of women, and some medical experts say that they are seeing more patients in their 20s and 30s, many of them nonsmokers. The disease takes more lives than breast, prostate, colon, and pancreatic cancers combined, and its survival rate is only 16 percent. Besides smoking, exposure to second-hand smoke, asbestos, radon or having a family history can put women at risk. The average incidence rate for cancers of the lung and bronchus during 2005-2009 was 20\% higher in African American men than in white men. The declines in lung cancer death rates are the result of decreases in smoking prevalence over the previous 40 years.

Pancreatic cancer is diagnosed in African Americans more often than in other racial/ethnic groups in the United States. When NFL Hall of Famer Gene Upshaw died of pancreatic cancer in 2008, it was the first time many Americans had heard of the disease. One reason for this lethality is that early pancreatic cancer often causes no symptoms. By the time doctors detect the disease, it has usually spread beyond the pancreas. Once that happens, it is rarely curable. Pancreatic cancer death rates in whites and blacks have gone in opposite directions over the past several decades in the United States. Current treatments for patients with pancreatic cancer include surgery, radiation therapy, chemotherapy, chemoradiation therapy, and targeted therapy.

Prostate cancer is the leading cancer diagnosed in men in the United States. During 2005-2009, the average annual prostate cancer incidence rate among African American men was 63\% higher than the rate in white men. The only well-established risk factors for prostate cancer are age, race, and family history of the disease. The incidence of pancreatic cancer is $50-90 \%$ higher in African Americans than in any other racial group in the United States. Genetic factor may be associated with the increased risk of prostate cancer amongst African Americans as they have higher incidence of K-ras mutations than Caucasians; and mutated K-ras has been associated with pancreatic cancer, which is a target for therapy. Prostate cancer in African American men is associated with specific changes in the IL-16 gene, according to researchers at the University of Illinois at Chicago College of Medicine. Exposure to heterocyclic amines may increase prostate cancer risk. Human sulfotransferase 1A1 (SULT1A1) is involved in the bioactivation of some dietary procarcinogens. The COX-2 gene promoter haplotypes may also influence the risk and development of prostate cancer. Elevated expression of PCGEM1, a prostate-specific gene with cell growth-promoting function, is associated with highrisk prostate cancer patients. Germ-line mutations of the Macrophage Scavenger Receptor 1 (MSR1) gene are associated with prostate cancer risk. A genome-wide scan of high-risk prostate cancer families in North America has demonstrated linkage of a particular marker to Chromosome 1q (HPC1). The Digital Rectal Examination (DRE) and the Prostate Specific Antigen (PSA) are the available diagnosis at present.

Skin cancer in the form of Basal Cell Carcinoma (BCC) is the most common cancer in Caucasians, but Squamous Cell Carcinoma (SCC) is the most common skin cancer among African Americans. Despite overall improvements in care across all races over the years, African Americans still suffer the greatest burden for the most common types of cancer. African Americans are more likely to die from melanoma, the deadliest form of skin cancer than are whites. A paper published in the journal Dermato-Endocrinology points the finger at a seemingly obvious but overlooked culprit: the sun. The researchers' theory is that, in northern latitudes, the dark skin of African Americans cannot absorb enough sunlight to generate adequate amounts of vitamin $\mathrm{D}$, which is often called the "sunshine vitamin." The body uses ultraviolet rays from the sun to manufacture vitamin $\mathrm{D}$ in the inner layers of the skin. Studies have shown that low levels of vitamin D in the blood seem to contribute to a weak immune system and a host of diseases, such as cancer and multiple sclerosis.

Esophageal cancer is the $8^{\text {th }}$ most common cancer and the $6^{\text {th }}$ most common cause of cancer deaths worldwide. Esophageal Adenocarcinoma (EAC) is the most common type in the United States and it begins in mucus secreting glands in the lower portion of the esophagus, while Esophageal Squamous Cell Carcinoma (ESCC) is the most prominent type worldwide and most often begins in the middle of the esophagus. Drinking alcohol, smoking or chewing tobacco, being obese, having Gastroesophageal Reflux Disease (GERD) can lead to esophageal cancer.

This publication is intended to provide information to cancer control advocates, community leaders, public health and health care workers, and other interested in cancer prevention, early detection, and treatment for African Americans. Effective programs must incorporate community participation, innovative outreach, use of social networks and trusted social institutions. Programs that include these strategies are much more likely to be effective in reducing cancer incidence. At Edward Waters College, through the OneFlorida Cancer Control Alliance's "Minority Education Program", we are determined to increase awareness of prevention, early detection and treatment tools (tobacco control efforts, screening for breast and colorectal cancer, and the dissemination of state-of-the-art cancer therapies) that can help everyone in our community to lead healthier lives.

\section{References}

1. http://www.census.gov/ipc/www/usinterimproj/

2. http://www.census.gov/2010census/news/press-kits/summary-file-1.htm

3. Us Census Bureau (2012) Place Of Birth For The Foreign-Born Population In The United States; 2006-2010 American Community Survey Selected Population Tables. American Fact Finder. U.s. Department Of Commerce.

4. SEER Cancer Statistics Review, 1975-2009 (Vintage 2009 Populations) Bethesda, MD: National Cancer Institute.

5. Arias E (2012) United States life tables, 2008. Natl Vital Stat Rep 61: 1-63.

6. Ward E, Halpern M, Schrag N, Cokkinides V, DeSantis C, et al. (2008) Association of insurance with cancer care utilization and outcomes. CA Cancer J Clin 58: 9-31.

7. Bach PB, Schrag D, Brawley OW, Galaznik A, Yakren S, et al. (2002) Survival of blacks and whites after a cancer diagnosis. JAMA287:2106-2113.

8. Shavers VL, Brown ML (2002) Racial and ethnic disparities in the receipt of cancer treatment. J Natl Cancer Inst94: 334-357.

9. Smedley BD, Stith AY, Nelson AR (2003) Unequal treatment: confronting racial and ethnic disparities in health care. Committee on Understanding and Eliminating Racial and Ethnic Disparities in Health Care. Washington, DC: National Academy Press, USA.

10. Jemal A, Clegg LX, Ward E, Ries LA, Wu X, et al. (2004) Annual report to the nation on the status of cancer, 1975-2001, with a special feature regarding survival. Cancer 101: 3-27.

11. Komenaka IK, Martinez ME, Pennington RE Jr, Hsu CH, Clare SE, et al. (2010) Race and ethnicity and breast cancer outcomes in an underinsured population. J Natl Cancer Inst 102:1178-1187. 
Citation: Mandal A, Islam NK, Scott J, Okafor B, Mandal PK (2014) African Americans and Cancer: A Minority Health Advocacy. J Bioprocess Biotech 4:e117 doi: 10.4172/2155-9821.1000e117

Page 3 of 2

12. Carey LA, Perou CM, Livasy CA, Dressler LG, Cowan D, et al. (2006) Race, breast cancer subtypes, and survival in the Carolina Breast Cancer Study. JAMA295: 2492-2502.

13. Li Cl, Malone KE, Daling JR (2002) Differences in breast cancer hormone receptor status and histology by race and ethnicity among women 50 years of age and older.Cancer Epidemiol Biomarkers Prev11: 601-607.

14. Chlebowski RT, Chen Z, Anderson GL, Rohan T, Aragaki A, et al. (2005) Ethnicity and breast cancer: factors influencing differences in incidence and outcome. J Natl Cancer Inst97:439-448.
15. Jemal A, Simard EP, Dorell C, Noone AM, Markowitz LE, et al. (2013) Annual Report to the Nation on the Status of Cancer, 1975-2009, Featuring the Burden and Trends in Human Papillomavirus (HPV)-Associated Cancers and HPV Vaccination Coverage Levels. J Natl Cancer Inst 1-27.

16. Wolin KY, Yan Y, Colditz GA (2011) Physical activity and risk of colon adenoma a meta-analysis. Br J Cancer 104: 882-885. 